\title{
KAJIAN LANDASAN HUKUM TERKAIT TUGAS POKOK DAN FUNGSI APOTEKER SEBAGAI PELAKSANA PENGADAAN PERBEKALAN FARMASI DI RUMAH SAKIT
}

\author{
Kristina M.L. ${ }^{1}$, R. Ayu Indah K.M. ${ }^{2}$, Ni Putu Yesi A.D. ${ }^{3}$, Ni Luh Gede Wiwin P. ${ }^{4}$, \\ Ni Made Widi A. ${ }^{5}$ \\ ${ }^{1}$ Program Studi Profesi Apoteker, Fakultas Matematika dan Ilmu Pengetahuan Alam \\ Universitas Udayana \\ E-mail: megilimba213@gmail.com
}

\begin{abstract}
ABSTRAK
Pengelolaan perbekalan farmasi merupakan salah satu pelayanan kefarmasian di Instalasi Farmasi Rumah Sakit. Produk dan jumlah obat yang mencukupi merupakan salah satu aspek penting dalam memberikan pelayanan yang terbaik. Studi ini bertujuan untuk membahas dasar-dasar hukum mengenai tugas pokok dan fungsi apoteker dalam pengelolaan obat, khususnya pengadaan perbekalan farmasi di rumah sakit. Penelitian ini menggunakan metode analisis deskriptif. Kajian pustaka yang digunakan berupa jurnal ilmiah dan peraturan perundang-undangan yang berkaitan dengan pengelolaan perbekalan farmasi pada tahap pengadaan. Dasar hukum yang mengatur pengadaan perbekalan farmasi adalah Permenkes RI No.72 Tahun 2016 Tentang Standar Pelayanan Kefarmasian di Rumah Sakit dan beberapa peraturan lain yang mendukung. Hasil kajian yang diperoleh berdasarkan kajian pustaka adalah pengelolaan kegiatan kefarmasian di Rumah Sakit pada tahap pengadaan perbekalan farmasi dilakukan IFRS yang dipimpin oleh apoteker. Pengelolaan perbekalan farmasi di rumah sakit dilakukan dengan sistem satu pintu karena dapat mempermudah proses pengawasan dan pengendalian perbekalan farmasi sesuai tujuan pengadaan yang diatur dalam Permenkes RI No.72 Tahun 2016.
\end{abstract}

Kata kunci: pengelolaan perbekalan farmasi, pengadaan, IFRS, system satu pintu, peraturan perundangundangan.

\begin{abstract}
Management of pharmaceutical supplies is one of the pharmaceutical services in Hospital Pharmacy Installations. In the management process, the procurement stage greatly affects the availability of drugs and the hospital economy. Guaranteed product and sufficient amount of medicine is one of the most important aspects of a hospital to be able to provide the best service. This study aims to discuss the legal basics regarding the main duties and functions of pharmacists in drug management, particularly the procurement of pharmaceutical supplies in hospitals. This research uses descriptive analysis method. Literature used in the form of scientific journals and regulations related to the management of pharmaceutical supplies at the procurement. The legal basis that regulates the procurement of pharmaceutical supplies is Permenkes RI No.72 Tahun 2016 Tentang Standar Pelayanan Kefarmasian di Rumah Sakit and several other supporting regulations. The results of the literature study were the management of pharmaceutical activities in the hospital at the stage of procurement of pharmaceutical supplies carried out by IFRS led by pharmacists. Management of pharmaceutical supplies in hospitals is carried out with a one-door system because it can simplify the process of supervising and controlling pharmaceutical supplies, according to the procurement objectives stated in the Permenkes RI No. 72 Tahun 2016.
\end{abstract}


Keywords: management of pharmaceutical supplies, procurement, one door system, laws and regulations.

\section{PENDAHULUAN}

Rumah sakit merupakan institusi pelayanan kesehatan yang menyediakan pelayanan kesehatan perorangan secara paripurna. Pelayanan yang disediakan salah satunya adalah pelayanan kefarmasian, termasuk pengelolaan perbekalan farmasi di rumah sakit. Permenkes RI No 72 tahun 2016 tentang Standar Pelayanan Kefarmasian di Rumah Sakit, menyatakan siklus pengelolaan perbekalan farmasi mencakup kegiatan perencanaan, pengadaan, penerimaan, penyimpanan, pendistribusian, pemusnahan dan penarikan, serta administrasi yang berisi pencatatan dan pelaporan.

Pengelolaan perbekalan farmasi di Rumah Sakit harus dilaksanakan secara efektif dan efisien karena memegang peranan penting dalam ketersediaan obat di rumah sakit. Obat harus terjamin mutunya dan memiliki harga yang terjangkau, selalu tersedia dan mencukupi ketika dibutuhkan. Rumah sakit dapat menerima dampak yang negatif secara medis maupun ekonomis jika terjadi ketidakefektifan dalam melakukan pengelolaan perbekalan farmasi. Dampak negatif yang mungkin dapat terjadi adalah peningkatan biaya pengadaan obat serta terganggunya kegiatan operasional pelayanan di rumah sakit.[1]
Pada proses pengelolaan, tahap pengadaan perbekalan farmasi memiliki pengaruh yang cukup besar dalam ketersediaan perbekalan farmasi dan ekonomi rumah sakit. Pengadaan perbekalan farmasi merupakan serangkaian kegiatan yang bertujuan untuk pemenuhan kebutuhan perbekalan farmasi sesuai dengan perencanaan.[2] Pengadaan harus dilakukan sesuai rencana, sesuai kemampuan, dan sesuai ketentuan.[3] Aspek penting untuk mewujudkan pelayanan terbaik dirumah sakit salah satunya adalah terjaminnya produk dan jumlah obat yang mencukupi. Rumah sakit mengeluarkan biaya yang besar pada pengelolaan perbekalan farmasi, terutama pada tahap pengadaan.[4]

Proses pengadaan perbekalan farmasi di rumah sakit memiliki pengaruh yang cukup besar pada sistem pelayanan dan ekonomi rumah sakit. Sehingga, pengadaan perbekalan farmasi perlu dilakukan sesuai dengan peraturan yang berlaku, demi meningkatkan mutu pelayanan di Rumah Sakit khususnya dalam bidang kefarmasian. Penyusunan artikel ini bertujuan untuk membahas dasar-dasar hukum mengenai tugas pokok dan fungsi apoteker dalam pengelolaan perbekalan farmasi, khususnya pada bagian pengadaan. 


\section{METODE PENELITIAN Metode}

Metode yang digunakan dalam penyusunan artikel ini adalah metode analisis deskriptif yakni menggambarkan suatu keadaan secara obyektif.[5] Pencarian sumber dilakukan dengan mengambil referensi (study literature) berupa jurnal ilmiah dan peraturan perundang-undang mengenai standar pelayanan kefarmasian di Rumah Sakit yang berkaitan dengan sumber data pengelolaan perbekalan farmasi pada tahap pengadaan. Adapun kriteria yang digunakan antara lain, jurnal ilmiah merupakan naskah publikasi 10 tahun terakhir (tahun 2010-2020), peraturan perundangundang yang digunakan merupakan peraturan perundang-undang terbaru mengenai standar pelayanan kefarmasian di Rumah Sakit, dan berisi mengenai pengelolaan perbekalan farmasi pada tahap pengadaan.

\section{HASIL dan PEMBAHASAN}

Rumah sakit adalah salah satu fasilitas kesehatan yang memberikan pelayanan kesehatan bagi masyarakat. Terciptanya suatu pelayanan kesehatan yang bermutu tentunya harus melibatkan berbagai tenaga kesehatan di dalamnya, salah satunya adalah apoteker. Apoteker memiliki peranan dalam memberikan pelayanan kefarmasian yakni berkaitan dengan perbekalan farmasi sehingga dapat meningkatkan mutu kehidupan pasien. Undang-Undang Nomor 44 tahun 2009 tentang Rumah 93
Sakit Pasal 15 Ayat (2) menyebutkan pelayanan mengenai sediaan farmasi khususnya di rumah sakit harus mengikuti standar pelayanan kefarmasian.

IFRS yang dipimpin oleh apoteker adalah suatu unit pelaksana fungsional yang memiliki tugas untuk menyelenggarakan pelayanan kefarmasian di Rumah Sakit. Kepala IFRS dalam menjalankan tugasnya akan dibantu oleh beberapa apoteker yang memiliki kompetensi secara profesional dan telah memiliki izin.[2] IFRS memiliki dua fungsi utama yaitu sebagai unit pelayanan dan sebagai unit produksi. Fungsinya sebagai unit pelayanan dibagi menjadi dua yakni pelayanan manajemen yakni menyediakan logistik dan administrasi dan pelayanan klinik yang bersentuhan langsung dengan pasien dan tenaga kesehatan lainnya.[7]

Sesuai dengan ketentuan dalam Pasal 15 ayat (3) UU Nomor 44 Tahun 2009 yakni pengelolaan perbekalan farmasi di Rumah Sakit dilakukan IFRS dengan menerapkan sistem satu pintu. Sistem satu pintu merupakan suatu kebijakan dalam bidang kefarmasian dengan ruang lingkup pembuatan formularium Rumah Sakit, pengadaan perbekalan farmasi, dan pendistribusian perbekalan farmasi di Rumah Sakit. Sistem satu pintu menegaskan bahwa seluruh perbekalan farmasi yang beredar di lingkungan Rumah Sakit adalah sepenuhnya tanggungjawab IFRS. Maka, akan sangat jelas bahwa tidak satupun kegiatan pengelolaan

Kristina M.L., R. Ayu Indah K.M., Ni Putu Yesi A.D., Ni Luh Gede Wiwin P., Ni Made Widi A. Program Studi Profesi Apoteker, Fakultas Matematika dan Ilmu Pengetahuan Alam 
perbekalan farmasi di Rumah Sakit dilaksanakan oleh unit lain selain IFRS. Sistem satu pintu bertujuan untuk mengutamakan keselamatan pasien melalui IFRS. Manfaat dari kebijakan pengelolaan sistem satu pintu antara lain proses pengawasan dan pengendalian lebih mudah, pengendalian harga perbekalan farmasi, mutu perbekalan farmasi terjamin, terjadinya penurunan risiko kesalahan daripada penggunaan perbekalan farmasi, data yang diakses lebih akurat, serta peningkatan mutu pelayanan.[2]

Sistem satu pintu salah satu lingkupnya adalah kegiatan pengadaan. Pengadaan merupakan serangkaian kegiatan penting untuk mendukung pelayanan. Hal ini dikarenakan proses pengadaan memiliki peranan dalam menjamin ketersediaan dari semua perbekalan farmasi. Kegiatan pengadaan ini bertujuan untuk meningkatkan efektifitas dan efisiensi pelaksanaan pengelolaan perbekalan farmasi dan farmakoekonomi. Pengadaan yang efektif adalah pengadaan yang mampu menjamin ketersediaan dan jumlah perbekalan farmasi, dengan harga yang terjangkau, waktu yang tepat, dan memiliki kualitas sesuai standar mutu. [2]

Pengadaan adalah tahapan untuk merealisasikan perencanaan perbekalan farmasi. Pengadaan perbekalan farmasi dilakukan oleh tenaga kefarmasian seperti yang dicantumkan pada PP RI No. 51 tahun 2009 Pasal 6 ayat (2) yakni yang tergabung dalam IFRS.
Pengadaan adalah proses yang berkesinambungan dan kompleks yang meliputi pemilihan item yang akan diadakan, penentuan jumlah perbekalan yang akan diadakan, penyesuaian antara dana yang ada dan kebutuhan, pemilihan metode untuk pengadaan, kriteria pemilihan pemasok, hal-hal yang menjadi kesepakatan dengan pemasok, evaluasi proses pengadaan, hingga pembayaran. [2] Secara garis besar prosedur pengadaan dapat dilihat pada bagan berikut.

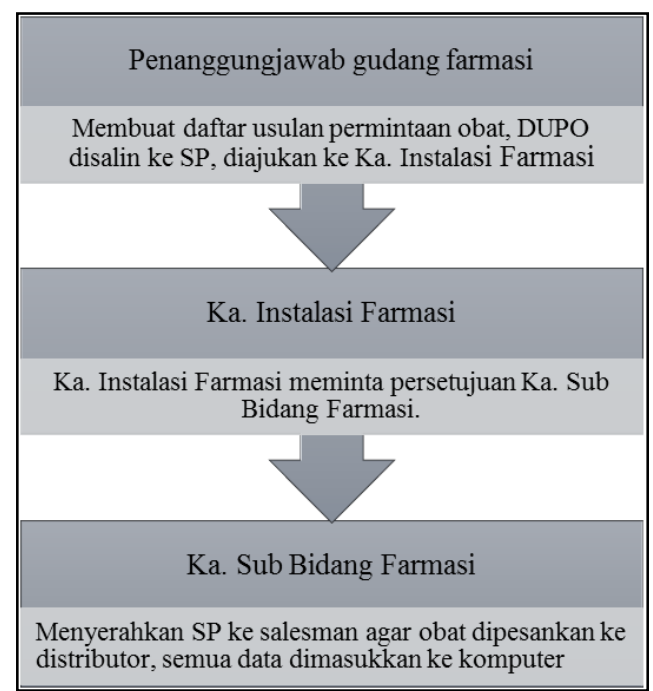

Gambar 1. Bagan Prosedur Pengadaan Perbekalan Farmasi di Rumah Sakit.[8]

Berdasarkan bagan tersebut dapat dijelaskan bahwa penanggungjawab gudang farmasi melakukan prosedur pengadaan obat di rumah sakit dengan membuat DUPO (daftar usulan permintaan obat) dan perbekalan farmasi lain. Daftar usulan ini dibuat berdasarkan kebutuhan 
pada tiap depo maupun instalasi. DUPO kemudian disalin dalam format SP (surat pesanan) setelah disetujui oleh kepala instalasi farmasi. Ka. instalasi farmasi selanjutnya meminta persetujuan kepada ka. sub bidang farmasi yang mempunyai anggaran pengadaan. Setelah disetujui, tahap terakhir yaitu Ka. sub bidang farmasi memberikan SP kepada salesman agar dipesankan kepada distributor. Seluruh data produk yang dipesan harus diinputkan pada sistem sebagai dokumentasi.[8]

Secara rinci prosedur pengadaan terdiri dari beberapa tahap penting. Hal penting yang harus diperhatikan sebelum melakukan proses pengadaan adalah perencanaan. Perencanaan merupakan proses penyusunan daftar perbekalan farmasi secara sistematik sehingga dapat mencapai tujuan yang telah ditetapkan. Perencanaan bertujuan untuk menyediakan dalam keadaan yang cukup sehingga tidak mengalami kekurangan ataupun kelebihan, serta mampu meningkatkan penggunaan secara efektif dan efisien. [2]

Sesuai dengan yang telah dijelaskan sebelumnya bahwa pengadaan terdiri dari serangkaian proses atau tahapan. Berikut adalah tahapan dari pengadaan.

\section{Pemilihan Item yang Diadakan}

Tahapan ini termasuk ke dalam bagian perencanaan. Kegiatan dalam tahap ini adalah memilih jenis perbekalan yang akan disediakan. Perbekalan yang disediakan disini harus benar-benar diperlukan sehingga tidak menghabiskan anggaran dan ruang penyimpanan untuk perbekalan yang tidak terlalu dibutuhkan. Pemilihan perbekalan farmasi ini harus mempertibangkan berbagai aspek salah satunya adalah mutu dari item tersebut [7].

2. Metode Pengadaan dalam Menentukan Jumlah Perbekalan

Penentuan jumlah dapat dilakukan dengan beberapa metode yakni metode konsumsi, ABC (Activity Based Costing), VEN dan morbiditas. Metode konsumsi merupakan metode penentuan berdasarkan data penggunaan di tahun-tahun sebelumnya.[9] Metode ABC berdasarkan jumlah dana yang dikeluarkan untuk setiap produk, dan diurutkan dari yang mengeluarkan biaya terbesar ke yang terkecil. Metode VEN berdasarkan seberapa penting dan dibutuhkan ketersediaan barang tersebut.[6] Metode morbiditas (epidemiologi) berdasarkan pada jumlah pasien yang hadir, waktu yang dibutuhkan pasien untuk menunggu, kejadian penyakit yang umum terjadi, serta pola dari perawatan standar [7].

3. Penyesuaian Antara Kebutuhan dan Dana

Hal terpenting yang harus diperhatikan saat pengadaan perbekalan farmasi yaitu keberadaan dana atau anggaran yang tersedia. Apoteker harus membuat anggaran dengan mempertimbangkan sumber dana dan besaran dana yang ada dengan keperluan perbekalan [6]. 95

Kristina M.L., R. Ayu Indah K.M., Ni Putu Yesi A.D., Ni Luh Gede Wiwin P., Ni Made Widi A. Program Studi Profesi Apoteker, Fakultas Matematika dan Ilmu Pengetahuan Alam Universitas Udayana 
4. Pemilihan Metode Pengadaan

Metode pengadaan yang umum digunakan yaitu pembelian dari distributor, produksi sendiri sediaan farmasi, dan sumbangan/dropping/ hibah. Metode yang dipilih harus disesuaikan dengan jenis kebutuhan Rumah Sakit [2].

A. Pembelian

Pembelian dapat dilakukan melalui lima metode yang umum digunakan yaitu tender terbatas, tender terbuka, pembelian dengan sistem tawar menawar, pembelian langsung, dan E-catalogue.

B. Produksi Perbekalan Farmasi Produksi sendiri perbekalan farmasi merupakan kegiatan untuk menghasilkan produk baru dengan kriteria tertentu yang hanya dapat dilakukan di Rumah Sakit tersebut dan ditujukan guna memenuhi kebutuhan pelayanan. [2] [6]

C. Sumbangan/Dropping/Hibah Penyedia perbekalan farmasi dapat menyediakan perbekalan farmasi yang sesuai dengan kebutuhan pasien di Rumah Sakit tersebut. Pimpinan Rumah Sakit atas rekomendasi Instalasi Farmasi dapat mengembalikan atau menolak sumbangan/dropping/hibah, jika perbekalan farmasi yang diberikan tidak dibutuhkan Rumah Sakit. [2] [6]
5. Pemilihan Pemasok

Pemasok pada umumnya adalah Pedagang Besar Farmasi (PBF) atau dapat pula Industri Farmasi. Pemilihan pemasok merupakan salah satu tahapan penting dalam pengadaan. Pemilihan ini dilakukan dengan tujuan untuk mendapatkan pemasok dengan produk yang bermutu dan harga terjangkau serta memiliki lead time yang cepat.[10]

6. Penentuan Kesepakatan

Hal-hal yang perlu disepakati oleh IFRS dan pemasok adalah sebagai berikut. [10]

a) Kesepakatan Tentang Jaminan Mutu Pasokan

b) Kesepakatan Mengenai Metode Verifikasi

c) Kesepakatan Untuk Penyelesaian Perselisihan

7. Evaluasi Proses Pengadaan

Proses evaluasi dilakukan untuk mengetahui sejauh mana keefektifan proses pengadaan yang dilakukan. Tujuannya untuk mengetahui hal apa yang harus dioptimalkan dalam pengadaan perbekalan farmasi selanjutnya. [11]

Secara keseluruhan, terdapat 3 elemen penting yang harus diperhatikan selama pengadaan. Tiga elemen penting tersebut yaitu pemilihan pengadaan yang dipilih, penyusunan dan persyaratan kontrak kerja, serta pemesanan barang agar sesuai macam, waktu, dan tempat, dan rentang kedaluarsa obat juga perlu diperhatikan.[6] Apoteker harus mampu memastikan bahwa Sertifikat 
Analisa dimiliki oleh seluruh bahan baku obat, Material Safety Data Sheet (MSDS) disertakan untuk bahan berbahaya, Nomor Izin Edar dimiliki oleh seluruh bahan medis habis pakai, memiliki masa kadaluarsa minimal 2 tahun kecuali untuk perbekalan farmasi tertentu misalnya vaksin dan reagensia. [2]

Pengadaan perbekalan farmasi di Rumah Sakit harus selalu melibatkan tenaga kefarmasian untuk memastikan mutu dan spesifikasi telah sesuai dengan persyaratan. Hal ini sesuai dengan ketentuan dalam UU No 36/2009 Tentang Kesehatan bahwa kegiatan pengadaan, penyimpanan, promosi, pengolahan, dan pengedaran obat tidak boleh dilakukan oleh setiap orang yang tidak ahli dan tidak berwenang dalam bidangnya. Kebijakan ini sejalan dengan penjaminan mutu obat yang beredar seperti yang diatur dalam SK Menkes No.189/ Menkes/ SK/ III/2006 tentang Kebijakan Obat Nasional (KONAS) bahwa semua obat yang beredar harus terjamin keamanan, khasiat dan mutunya agar memberikan manfaat bagi Kesehatan. KONAS memiliki tujuan untuk menjamin pemerataan, ketersediaan obat, keterjangkauan obat, serta mampu menjamin mutu, khasiat, dan keamanan obat, mencegah penyalahgunaan obat dan penggunaan obat yang salah, serta dapat menjamin rasionalnya penggunaan obat.

\section{KESIMPULAN}

Berdasarkan studi literatur yang dilakukan, kesimpulan yang dapat 97 diambil yaitu ketentuan tentang pengadaan perbekalan farmasi diatur dalam Permenkes RI No.72 Tahun 2016 Tentang Standar Pelayanan Kefarmasian di Rumah Sakit serta peraturan lain yang mendukung. Pengelolaan perbekalan farmasi di Rumah Sakit pada tahap pengadaan dilakukan oleh IFRS yang dipimpin oleh apoteker. Pengelolaan perbekalan farmasi dilakukan dengan sistem satu pintu. Sistem ini dapat mempermudah pengawasan dan pengendalian perbekalan farmasi. Pengadaan perbekalan farmasi yang efektif dan efisien mampu menjamin tersedianya perbekalan farmasi yang bermutu, aman, dan berkhasiat. Pengadaan yang tepat akan mendukung pelayanan kefarmasian di Rumah Sakit.

\section{UCAPAN TERIMA KASIH}

Ucapan terima kasih disampaikan kepada semua pihak yang selalu mendukung dan berpartisipasi langsung dalam penulisan artikel ini.

\section{DAFTAR PUSTAKA}

[1] Febreani, S.H. dan D. Chalidyanto. 2016. Pengelolaan Sediaan Obat Pada Logistik Farmasi Rumah Sakit Umum Tipe B di Jawa Timur. Jurnal Administrasi Kesehatan Indonesia Vol.4(2): 136-145.

[2] Permenkes RI. 2016. Peraturan Menteri Kesehatan Nomor 72 tahun 2016 tentang Standar Pelayanan Kefarmasian di Rumah Sakit. Jakarta: Menteri Kesehatan Republik Indonesia.

Kristina M.L., R. Ayu Indah K.M., Ni Putu Yesi A.D., Ni Luh Gede Wiwin P., Ni Made Widi A. Program Studi Profesi Apoteker, Fakultas Matematika dan Ilmu Pengetahuan Alam Universitas Udayana 
[3] Seto, S., Y. Nita, dan L. Triana. (2012). Manajemen Farmasi Lingkup: Apotek, Farmasi, Rumah Sakit, Pedagang Besar Farmasi, Instalasi Farmasi. Edisi Tiga. Surabaya: Airlangga University Press.

[4] Mahdiyani,U.,C.

Wiedyaningsih, dan D. Endarti. 2018. Evaluasi Pengelolaan Obat Tahap Perencanaan dan Pengadaan di RSUD Muntilan Kabupaten Magelang Tahun 2015-2016. JMPF Vol.8(1):2431.

[5] Dadiani, N.M., W. A. Lolo., I. Antasionasti. 2020. Persepsi Perawat Terhadap Peran Apoketer Dalam Pelayanan Kefarmasian Di Rumah Sakit Robert Wolter Mongisidi Manado. Pharmacon. 9(2): 310317.

[6] Direktorat Jenderal Bina Kefarmasian. 2010. Pedoman Pengelolaan Perbekalan Farmasi di Rumah Sakit. Jakarta: Kementerian Kesehatan Republik Indonesia.

[7] Rusli. 2016. Farmasi Rumah Sakit dan Klinik. Jakarta: Kementerian Kesehatan Republik Indonesia.

[8] Larasati, I., Susilo, H., dan Riyadi. 2013. Analisis Sistem Informasi Manajemen Persediaan Obat. Jurnal Administrasi Bisnis 1(5):57-67.

[9] Walujo, D.S., P.E. Yudha, F.A. Septria. 2018. Analisis Perencanaan Obat dengan Menggunakan Metode
Konsumsi di Instalasi Farmasi Dinas Kesehatan Kota Kediri Tahun 2017. Jurnal Wiyata 5(10):24-28.

[10] Siregar, C.J.P. 2004. Farmasi Rumah Sakit: Teori dan Penerapan. Jakarta: Penerbit Buku Kedokteran EGC.

[11] Oktaviani, N., G. Pamudji, dan Y.Kristanto. 2018. Evaluasi Pengelolaan Obat Di Instalasi Farmasi Rumah Sakit Umum Daerah Provinsi NTB Tahun 2017. Jurnal Farmasi Indonesia Vol.15(2): 135-147.

[12] Departemen Kesehatan Republik Indonesia. 2009. Peraturan Pemerintah Republik Indonesia Nomor 51 Tahun 2009 tentang Pekerjaan Kefarmasian. Jakarta: Departemen Kesehatan Republik Indonesia.

[13] Kemenkes RI. 2006. Keputusan Menteri Kesehatan Republik Indonesia Nomor 189/Menkes/SK/III/2006

Tentang Kebijakan Obat Nasional. Jakarta: Menteri Kesehatan Republik Indonesia.

[14] UU RI. 2009. Undang-Undang Republik Indonesia Nomor 36 Tahun $2009 \quad$ Tentang Kesehatan. Jakarta: Presiden Republik Indonesia.

[15] UU RI. 2009. Undang-Undang Republik Indonesia Nomor 44 Tahun 2009 Tentang Rumah Sakit. Jakarta: Presiden Republik Indonesia.

Kristina M.L., R. Ayu Indah K.M., Ni Putu Yesi A.D., Ni Luh Gede Wiwin P., Ni Made Widi A. Program Studi Profesi Apoteker, Fakultas Matematika dan Ilmu Pengetahuan Alam Universitas Udayana 